PROFESI (Profesional Islam): Media Publikasi Penelitian

2019; Volume 16; No 2.

Website: ejournal.stikespku.ac.id

\title{
Pengetahuan Kader Tentang Kekerasan Pada Anak
}

\author{
Rosmita Nuzuliana ${ }^{1^{*}}$, Diajeng Kenanga Ma'rifat ${ }^{2}$ \\ ${ }^{1,2}$ Prodi DIII Kebidanan Jenjang DIII, Fakultas Ilmu Kesehatan, Universitas 'Aisyiyah Yogyakarta \\ *Email: rosmitanz@unisayogya.ac.id
}

\begin{abstract}
Kata Kunci
Kekerasan,

Anak,

Kader,

Pengetahuan
\end{abstract}

\begin{abstract}
Abstrak
Kasus kekerasan terhadap perempuan dan anak sangat mempengaruhi kesehatan yang akan berdampak pada penurunan kualitas Sumber Daya Manusia (SDM). Oleh karena itu pelaporan yang segera bisa meminimalisir tindak kekerasan. Salah satu bagian dari masyarakat yang dapat dilibatkan dalam program prevensi dini kekerasan pada anak adalah kader posyandu, namun kader tidak menjalankan fungsinya karena mengganggap kasus kekerasan adalah wilayah domestic. Tujuan penelitian ini adalah pengetahuan kader tentang kekerasan pada anak. Jenis Penelitian ini adalah Observasional dengan rancangan cross sectional, menggunakan 210 responden, alat yang digunakan adalah kuisioner pengetahuan tentang kekerasan pada anak. analsis yang digunakan adalah analisis univariat. Hasil yang didapatkan bahwa mayoritas (70.5\%) kader memiliki tingkat pengetahuan tinggi dimana dari distribusi kuisioner rata rata paling banyak menjawab benar pada item pertanyaan terkait faktor penyebab dan jenis kekerasan pada anak.
\end{abstract}

\section{Cadre Knowledge About Violence in Children}

Key Words:

Violence,

Children,

Cadre

Knowledge

\begin{abstract}
Cases of violence against women and children greatly affect health which will affect the quality of Human Resources (HR). Therefore, immediately reporting nearb can minimize acts of violence. One part of the community that can be involved in the early prevention program for violence is posyandu cadres, however cadres do not function because they consider cases of violence to be domestic. The purpose of this study isto know the cadre's knowledge of child abuse. This research type was observational with a cross sectional design, using 210 respondents, the tool used questionnaire about child abuse. The analysis was univariate analysis. The results showed that the majority (70.5\%) of cadres had a high level of knowledge where the average distribution of questionnaires answered the most on questions related to the causes and types of violence on children
\end{abstract}

\section{PENDAHULUAN}

Kekerasan anak merupakan masalah global yang menyangkut hak asasi manusia. Masalah yang dari tahun ke tahun mengalami peningkatan. Data komisi nasional perlindungan tahun 2016 pada data survey tahun 2011-2016 menyebutkan bahwa kasus kekerasan terhadap anak menempati angka 44.541 kasus (KPAI, 2016). Sedangkan data KPAI (2016) di Daerah Istimewa Yogyakarta (DIY) menyebutkan bahwa kasus kekerasan pada anak dan perempuan mencapai angka 1.113 dari 44.541 (penyubang 2,5\% kekerasan seluruh
Indonesia). Jumlah kekerasan di kota Yogyakarta tahun 2015 sendiri menempati posisi kedua setelah Kabupaten Sleman dengan jumlah 383, angka ini mengalami penurunan dari 38 kasus dari tahun sebelumnya (BPPM DIY, 2016). Peningktan kasus kekerasan pada anak bisa disebabkan karena meningkatkanya kesadaran masyarakat dalam melapor kasus kekerasan dan faktor lingkungan yang tidak kondusif (Agustina, 2016). Lingkungan yang tidak kondusif bisa berupa lemahnya kontrol pengendalian belanja harian rumah tangga, yang lebih mengutamakan 
kebutuhan tersier seperi pulsa, bensin, dan rokok dari pada pemenuhan kebutuhan primer, 2) terjadinya konstriksi gender yang mengatakan cantik itu identik dengan langsing dan lain sebagainya, 3) dan rendahnya pola komunikasi keluarga yang tidak terbuka antara orang tua dan anak (BPPM DIY, 2016).

Kasus kekerasan terhadap perempuan dan anak sangat mempengaruhi kesehatan yang akan berdampak pada penurunan kualitas Sumber Daya Manusia (SDM). Oleh karena itu dibutuhkan pelayanan kesehatan secara komprehensif dan berkualitas. Pelayanan kesehatan bagi korban kekerasan pada anak dilakukan melalui pelayanan di tingkat dasar yaitu di Puskesmas (Kemenkes RI, 2009). Di tiga puskesmas Kota Yogyakarta, upaya pemerintah ini tidak serta merta di laksanakan oleh pihak puskesmas. Hal ini dikarenakan masing masing puskesmas memiki program kerja atau keunggulan masing masing puskesmas. Pihak Puskesmas jarang melakukan identifikasi atau deteksi dini kasus kekerasan di wilayah (Nuzuliana \& Istiati, 2017). Hal ini menunjukkan bahwa target pemerintah terhadap pendataan informasi baru sebatas pendataan kasus yang sudah pernah terjadi. Puskesmas belum mampu dalam mendeteksi masyarakat yang memiliki potensial terhadap kekerasan pada anak (Kemenkes RI, 2009).

Keterbatasan petugas puskesmas dalam mengungkap wilayah yang memiliki potensial terjadi kekerasan dikarenakan ketidakmampuan kader dalam menyampaikan kasus yang terjadi diwilayah sekitar. Kader merupakan salah satu bagian dari masyarakakt yang dilibatkan dalam upaya pencegahan kekerasan yang terjadi dilingkungannya. Kader yang dianggap sebagai tangan panjang petugas puskesmas pun tidak tidak berperan dalam proses identifikasi kasus kekerasan pada anak di lingkungan sekitarnya. Kader menganggap hal tersebut adalah wilayah domestik masing masing keluarga (Nuzuliana and Istiyati, 2017). Hal ini bertolak belakang dengan pendapat Fariani \& Paramastri (2015) Salah satu bagian dari masyarakat yang dapat dilibatkan dalam program prevensi dini kekerasan pada anak adalah kader posyandu. Kader posyandu merupakan salah satu wujud peran serta masyarakat dalam membantu upaya pelayanan kesehatan.

\section{METODE PENELITIAN}

Jenis Penelitian ini adalah Observasional dengan rancangan cross sectional dengan pendekatan kuantitatif. Populasi pada penelitian ini adalah kaer kesehatan yang ada di wilayah Puskesmas Mantrijeron. Dengan jumlah popolasi sebanyak 365 kader. Sampel yang digunakan adalah kader kesehatan yang ada di Puskesmas Mantrijeron. Dengan konsekutif sampling. Perhitungan jumlah sample dengan menggunakan rumus slovin dengan kesalahan 5\% sehingga didapatkan jumlah 190.84. untuk menghindari adanya sampel yang gugur maka diterapkan jumlah sampel yang didapat dikali $10 \%$ sehingga didapatkan 209.93 responden dan dibulatkan menjadi 210. Alat yang digunakan adalah kuisioner yang berisi karakteristik responden dan kuisioner tingkat pengetahuan tentang kekerasan anak. Kuisioner yang digunakan sudah dilakukan uji validitas dan uji reliabelitas yang dilakukan pada kader kesehatan di Wilayah Kerja Puskesmas Umbul Harjo I sejumlah 70 kader kesehatan. Jumlah kuisioner yang dilakukan uji validitas sejumlah 51 soal dengan dengan $r$ table 0.2284 dengan tingkat signifikansi 0.05 . Hasil soal yang valid sejumlah 31 soal. Nilai alfa cronbach sebesar 0.845 .

Pengambilan data diawali dari uji etik yang dilakukan komite etik Universitas 'Aisyiyiyah Yogyakarta nomor 379/KEP-UNISA/V/2018. Pengambilan data oleh satu asisten peneliti yang sudah dilakukan apersepsi terlebih dahulu. Data yang telah dikumpulkan diidentifikasi kelengkapannya kemudian dilakukan penyusunan data dan pelaporan. Analisis data yang digunakan adalah analisis univariat yang di tabulasi silang dengan karakteristik responden. Selain itu analisis yang digunakan adalah analisis soal yang ada di kuisioner.

\section{HASIL DAN PEMBAHASAN}

Puskesmas Mantrijeron terletak di Kota Yogyakarta, yang merupakan merupakan salah satu Kota yang ada di Daerah Istimewa Yogyakarta. Puskesmas Mantrijeron merupakan Puskesmas yang terakreditasi Paripurna Per tanggal 24 
PROFESI (Profesional Islam): Media Publikasi Penelitian 2019; Volume 16; No 2.

Website: ejournal.stikespku.ac.id

Desember 2015. Puskesmas telah dibekali pelatihan dalam tatalaksana kekerasan pada anak dan perempuan oleh dinas kesehatan Kota yogya yang bekerja sama dengan Pusat Pelayanan Terpadu Perlidungan Perempuan dan Anak (P2TP2A). Proses pelayanan terhadap korban kekerasan kepada anak di Puskesmas Mantrijeron dilaksanakan seperti pelayanan yang lain, hanya saja puskesmas memiliki tanda kusus pada rekam medis dalam membedakan kasus kekerasan. Dalam tatalaksana kasus kekerasan pada anak, puskesmas melayani ketika pasien datang, bukan dengan pelaksanaan jemput bola. Dalam upaya pemberdayaan masyarakat pihak puskesmas juga memberikan materi dan workshop kasus kekerasan pada anak kepada kader kesehatan.

Tabel 1. Tingkat Pengetahuan Kader Kesehatan Terkait Kekerasan Anak

\begin{tabular}{lcc}
\hline \multicolumn{1}{c}{ Karakteristik } & $\mathrm{n}$ & $\%$ \\
\hline Tingkat pengetahuan & & \\
Tinggi & 148 & 70.5 \\
Cukup & 53 & 25.3 \\
Rendah & 9 & 4.2 \\
Jumlah & 210 & 100 \\
\hline
\end{tabular}

Definisi tinggi rendah pengetahuan diambil dari peneltian Fissawati, Indriati, \& Elita, (2014) bahwa dikatakan berpengetahuan tinggi jika jawaban benar mencapai prosentase $\geq 76 \%$, sedang $56 \%-<76 \%$, sedangkan pengetahuan rendah apabila jumlah jawaban benar $<56 \%$. Dari tabel 1 disebutkan bahwa tingkat pengetahuan kader kesehatan mayoritas adalah berpengatuan tinggi 70.5\%. Notoadmojo dan Mubarok dalam (Rahmadhani, 2017) menjelaskan bahwa semakin tinggi tingkat pengetahuan seseorang semakin seseorang tersebut bersikap positif terhadap sesuatu hal. Apabila kader bersikap positif terhadap kasus kekerasan pada anak maka akan mempermudah proses indentifikasi kasus kekerasan pada anak. IDI et al., (2004) menjelaskan proses identifikasi kekerasan pada anak merupakan langkah awal dalam perlindungan dan penanganan kekerasan pada anak yang bisa dilakukan oleh tenaga professional medis, pengajar dan pendidik, pengasuh anak, tenaga profe- ssional mental, penegak hukum, agamawan, dan professional lainnya bahkan orang awam seperti keluarga lain tetangga dan teman atau bahkan kader kesehatan wilayah setempat.

Tabel 2. Tabulasi Silang Antara Karakteristik Kader Kesehatan dengan Tingkat Pengetahuan Kader

\begin{tabular}{|c|c|c|c|c|c|c|}
\hline & \multicolumn{6}{|c|}{ Tingkat Pengetahuan } \\
\hline & Tinggi & $\%$ & Sedang & $\%$ & Rendah & $\%$ \\
\hline \multicolumn{7}{|l|}{ Tingkat } \\
\hline \multicolumn{7}{|l|}{ Pendidikan } \\
\hline Tinggi & 132 & 62.9 & 51 & 24.3 & 9 & 4.3 \\
\hline Rendah & 16 & 7.6 & 2 & 1.0 & 0 & 0.0 \\
\hline \multicolumn{7}{|l|}{ Pengalaman } \\
\hline Punya & 76 & 36.2 & 26 & 12.4 & 7 & 3.3 \\
\hline Tidak Punya & 72 & 34.3 & 27 & 12.9 & 2 & 1.0 \\
\hline \multicolumn{7}{|l|}{ Status } \\
\hline $\begin{array}{l}\text { Pekerjaan } \\
\text { bekerja }\end{array}$ & \multicolumn{5}{|c|}{ Pekerjaan } & 2.9 \\
\hline tidak bekerja & 109 & 51.9 & 41 & 19.5 & 3 & 1.4 \\
\hline \multicolumn{7}{|l|}{ Lama } \\
\hline \multicolumn{7}{|l|}{ Menjadi } \\
\hline \multicolumn{7}{|l|}{ Kader } \\
\hline 9-11 bulan & 23 & 11.0 & 5 & 2.4 & 0 & 0.0 \\
\hline $0-<9$ bulan & 125 & 59.5 & 48 & 22.9 & 9 & 4.3 \\
\hline Usia & & & & & & \\
\hline $\begin{array}{l}20-50 \text { tahun } \\
<20\end{array}$ & 75 & 35.7 & 30 & 14.3 & 7 & 3.3 \\
\hline $\begin{array}{l}\text { tahun } \& />50 \\
\text { tahun }\end{array}$ & 73 & 34.8 & 23 & 11.0 & 2 & 1.0 \\
\hline
\end{tabular}

Dari hasi distribusi silang disebutkan bahwa tingkat pengetahuan kader yang tinggi terlihat pada kader yang memiliki tingkat pedidikan yang tinggi, memiliki pengalaman terkait dengan kasus kekerasan baik langsung maupun tidak langsung, kader yang tidak bekerja dan kader yang 0-9 bulan berpengalaman menjadi kader dan berusia produktif. Notoadmojo dan Mubarok dalam (Rahmadhani, 2017) menjelaskan pengetahuan adalah hasil pengindraan manusia, yang dipengaruhi oleh intensitas perhatian, pesepsi dan kesan didalam pikiran manusia. Tingkat pendidikan mempengaruhi tinggi rendahnya pngetahuan seseorang. Seseorang yang berpendidikan tinggi memliki kesempatan yang lebih besar dalam mendapatkan informasi. Pengalaman secara langsung maupun tidak langsung bisa menjadikan pengetahun seseorang tersebut meningkat (Fissawati, Indriati and Elita, 2014).

Mayoritas kader berusia produktif dan usia dewasa. Santrock dalam Fariani \& Paramastri (2015) menjelaskan bahwa usia mempengaruhi kemampuan individu dalam meningkatkan pe- 
ngetahuan. Kemampuan seseorang meningkat pada rentang usia 25-35 tahun, karena pada tahapan ini merupakan tahapan pencapaian (achieving stage), pada usia ini kader merasakan pentingnya mendapatkan pengetahuan, khususnya terkait kekerasan anak yang digunakan dalam mencapai tuuan mengasuh anak. Kader yang berpengetahuan tinggi pada kader junior yaitu kader yang berpengalaman selama 0-9 bulan, hal ini kemungkinan disebabkan karena kader baru rata rata berusia muda dan dalam mendapatkan informasi lebih runtut.

Tabel 2. Distribusi Frekuensi Rata Rata Jawaban

Benar Item Pertanyaan Terkait Kekerasan Pada Anak

\begin{tabular}{lc}
\hline \multicolumn{1}{c}{ Item Pertanyaan } & $\begin{array}{c}\text { Rata-rata Jawaban } \\
\text { Benar }(\%)\end{array}$ \\
\hline Definisi kekerasan pada anak & 55 \\
Faktor Penyebab Kekerasan & 86 \\
pada Anak & 73 \\
Jenis Kekerasan Pada Anak & 86 \\
Dampak kekerasan pada anak & 81.6 \\
Peran tenaga kesehatan & \\
terhadap kasus kekerasan pada & \\
anak & \\
\hline
\end{tabular}

\section{a. Tabulasi silang karakteristik kader kese-} hatan dengan Tingkat pengetahuan kader

Dari hasi distribusi silang disebutkan bahwa tingkat pengetahuan kader yang tinggi terlihat pada kader yang memiliki tingkat pedidikan yang tinggi, memiliki pengalaman terkait dengan kasus kekerasan baik langsung maupun tidak langsung, kader yang tidak bekerja dan kader yang 0-9 bulan berpengalaman menjadi kader dan berusia produktif. Notoadmojo dan Mubarok dalam (Rahmadhani, 2017) menjelaskan pengetahuan adalah hasil pengindraan manusia, yang dipengaruhi oleh intensitas perhatian, pesepsi dan kesan didalam pikiran manusia. Tingkat pendidikan mempengaruhi tinggi rendahnya pngetahuan seseorang. Seseorang yang berpendidikan tinggi memliki kesempatan yang lebih besar dalam mendapatkan informasi. Pengalaman secara langsung maupun tidak langsung bisa menjadikan pengetahun seseorang tersebut meningkat (Fissawati, Indriati and Elita, 2014).
Mayoritas kader berusia produktif dan usia dewasa. Santrock dalam Fariani \& Paramastri (2015) menjelaskan bahwa usia mempengeruhi kemampuan individu dalam meningkatkan pengetahuan. Kemapuan seseorang meningkat pada rentang usia 25-35 tahun, karena pada tahapan ini merupakan tahapan pencapaian (achieving stage), pada usia ini kader merasakan pentingnya mendapatkan pengetahuan, khususnya terkait kekerasan anak yang digunakan dalam mencapai tuuan mengasuh anak. Kader yang berpengetahuan baik pada kader junior yaitu kader yang berpengalaman selama 0-9 bulan, hal ini kemungkinan disebabkan karena kader baru rata rata berusia muda dan dalam mendapatkan informasi lebih runtut.

\section{b. Tingkat pengetahuan kader tentang defi- nisi kekerasan pada anak}

Penelitian menunjukkan bahwa rata rata responden menjawab benar tentang definisi kekerasan pada anak sebesar $54.76 \%$. sebanyak 115 kader memahami jika tindakan kekerasan pada anak adalah suatu tindakan yang membuat ketidaknyamanan pada anak. Menurut pasal 89 KUHP dalam (Jayanti and Lestari, no date) definisi kekerasan adalah suatu perbuatan dengan menggunakan tenaga atau kekuatan jasmani secara tidak sah, atau membuat orang tidak berdaya. Melakukan kekerasan artinya mempergunakan tenaga atau kekuatan jasmani tidak kecil tidak sah, misalnya memukul dengan tangan atau dengan segala macam senjata, menyepak, menendang dan sebagainya. Jika perbuatan tersebut dilakukan kepada anak maka disebut dengan bentuk kekerasan pada anak (child abuse).

Kekerasan pada anak adalah semua bentuk perlakuan yang menyakitkan baik secara fisik ataupun emosional, penyalahgunaan seksual, penelantaran eksploitasi komersial atau eksploitasi lain, yang mengakibatkan cedera atau kerugian secara nyata (terlihat langsung pada sat itu) ataupun secara potensial merugikan kesehatan anak, kelangsungan hidup anak, pertumbuhan dan perkembangan anak serta martabat anak, (IDI, Depkes RI and Unicef, 2004). Kekerasan pada anak juga bisa berupa pengabaian dan penelantaran, atau ketidakpedulian orangtua atau 
PROFESI (Profesional Islam): Media Publikasi Penelitian 2019; Volume 16; No 2.

Website: ejournal.stikespku.ac.id

orang lain pada kebutuhan anak baik kesehatan, pendidikan, tempat tinggal, keamanan dan kenyamanan (Paramastri, 2011)

\section{c. Tingkat pengetahuan kader tentang faktor penyebab kekerasan pada anak}

Rata-rata kader menjawab benar pada faktor penyebab kasus kekerasan pada anak adalah $86 \%$. Berdasarkan dari data yang terdapat di kuisioner bahwa faktor penyebab yang paling banyak diketahui oleh kader adalah adanya Sosial Psycological Model. Dalam penelitian ini faktor penyebab kekerasan pada anak dari adanya social psychological adalah terkait percekcokan orang tua (98\% kader menjawab benar) dan rendahnya pola komunikasi antar keluarga $(93 \%$ kader menjawab benar). Berdasarkan Juztice dan Justice dalam (Jayanti and Lestari, no date) disebutkan bahwa salah satu faktor yang memiliki hubungan sebab akibat dari tindak kekerasan pada anak adalah faktor sosial psycologikal model, pada model ini komuniasi antar keluarga yang tidak baik dan adanya percekcokan dengan orang tua bisa menjadikan frustasi dan stressor bagi orang tua sehingga anak bisa menjadi pelampiasan dan akibatnya anak mengalami kekerasan dari orang tuanya sendiri.

Salah satu faktor penyebab kasus kekerasan pada anak adalah sosial ekonomi keluarga. Keadaan sosial ekonomi tergambarkan pada kuisioner mengenai tingkat pendidikan orang tua (74 kader menjawab benar), ibu yang bekerja dan seorang kepala yang tidak bekerja merupa-kan salah satu penyebab kasus kekerasan pada anak. Pada pertanyaan tersebut $91 \%$ kader menjawab benar. Su'adah dalam Gumiarti (2008) menjelaskan bahwa orang tua yang bekerja, mempunyai nilai-nilai "tradisional", lebih menekankan pada kebersihan, kerapihan, kepatuhan dan menghormati orang dewasa. Mereka menginginkan anak sesuai dengan aturan/patokan yang diberikan dari luar, jadi takut untuk dinilai salah oleh orang lain. Nilai kejujuran merupakan sifat yang diciptakan Untuk memberikan kepercayaan pada orang lain (truthworthness). Pada orang tua dengan pekerjaan kelas pekerja, yang ditekankan adalah kepatuhan anak kepada orang tuanya. Hukuman diberlakukan langsung bila anak-anak tidak patuh, tanpa melihat sebab-sebabnya, dan sering berbentuk hukuman fisik.

Faktor yang lain adalah psychodynamic model dimana dalam kusioner tergambar pada orang tua tunggal. Terjadinya kekerasan pada anak disebabkan karena kurangnya "mothering imprint"/ (jejak ibu). Seorang anak yang tidak pernah merasakan dirawat atau diasuh oleh seorang ibu secara baik, maka dia tidak akan bisa menjadi ibu dan merawat anaknya sendiri (Jayanti and Lestari, no date).

\section{d. Tingkat pengetahuan kader tentang jenis- jenis kekerasan pada anak}

Kader menjawab benar tentang jenis kekerasan pada anak dengan rata rata menjawab benar $73 \%$. Jenis kekerasan yang diketahui kader baik. Jenis kekerasan pada anak pada table 4.3 menjabarkan beberapa jenis kekerasan yaitu memarahi, mengancam, mengeksploitasi, membandingkan. Putri \& Santoso (2012) menjelaskan bahwa anak pada usia 3-6 tahun rentan terjadi kekerasan verbal hal ini disebabkan karena pada usia tersebut anak lebih bersifat kreatif dalam mengeksplorasi lingkungan. Kreatifitas anak seringkali bersifat mengganggu orang tua sehingga orang tua tidak segan segan dalam melakukan kekerasan verbal seperti memarahi, dan kekerasan emosi seperti memberikan ancaman.

\section{e. Tingkat pengetahuan kader tentang dam- pak kekerasan pada anak}

Rata rata kader menjawab benar tentang dampak kekerasan pada anak adalah $86 \%$ dimana terjabarkan dari berbagai macam dampak kekerasan. Dampak yang dijabarkan pada data adalah anak lebih berisfat agresif (98\% kader menjawab benar pada dampak ini) pada kasus anak lebih agresif ini lebih ditunjukkan pada anak pada pelaku kekerasan. Anak merasa tidak nyaman dan tidak ada yang melindungi dirinya sehingga anak akan memukul dan melakukan tindakan agresif kepada sipelaku (Jayanti and Lestari, no date). dampak yang lain adalah adaya murung atau depresi. Murung atau depresi bisa ditandai dengan penurunan berat badan, pemurung, pendiam, minder dan kurang percaya diri. Pada poin ini $97 \%$ kader menjawab benar terkait 
minder dan tidak percaya diri adalah dampak yang muncul akibat kekerasan pada anak.

Hefler dan moro dalam Gowi, Hamid, \& Nuraini (2012) Perlakuan salah atau kekerasan pada anak akan berpengaruh pada gangguan psikologis, anak terlihat murung, tertutup, jarang beradaptasi dan bersosialisasi, kurang konsentrasi, serta prestasi akademik menurun. Tindakan dari korban penganiayaan fisik, anak menjadi negatif dan agresif, serta mudah frustasi, ada yang menjadi sangat pasif dan apatis; ada yang tidak mempunyai kepribadian sendiri; ada yang sulit menjalin hubungan dengan individu lain, dan ada pula yang timbul rasa benci yang luar biasa terhadap dirinya sendiri.

Dampak perlakuan agresif pada anak tidak hanya pada perkembangan emosi dan perilaku namun bisa mempengaruhi prestasi belajar atau dalam hal ini adalah penurunan intelegensi $(73 \%$ kader menjawab benar). Penurunan prestasi belajar akan menjadikan penurunan kualitas sumber daya manusia (92\% kader menjawab benar) (Setiawan, 2010). Kaufmann dalam Setiawan, (2010) menjelaskan bahwa anak yang agresif pada umumnya memiliki prestasi akademik yang rendah diusianya dan mayoritas memiliki kesulitan akademis dikarenakan memiliki kekurangan dalam ketramplan sosial yang mempengaruhi kemampuan untuk bekerjasama dengan guru.

\section{f. Tingkat pengetahuan kader tentang peran tenaga kesehatan terhadap kasus keke- rasan pada anak}

Rata rata kader menjawab benar tentang peran tenaga kesehatan terhadap kasus kekerasan pada anak adalah $81.6 \%$. Sejumlah $97 \%$ kader mengetahui dengan benar keberadaan kader merupakan bagian dari masyarakat yang dilibatkan dalam prevensi dini kekerasan pada anak dan perempuan. Sejumlah 98\% kader mengetahui bahwa kader harus berperan aktif dalam pelaporan kasus kekerasan pada anak. Kader mengetahui bahwa pelapor kasus kekerasan pada anak dilindungi Negara. Notoadmodjo dalam Fissawati et al. (2014) menjelaskan bahwa sikap atau perilaku terbentuk dari pengetahuan yang telah diperoleh. Dalam penelitian ini pengetahuan kader terkait perannya dalam kasus kekerasan adalah baik sehingga dapat sebagai salah satu modal dalam bersikap positf dalam pelaporan kasus kekerasan pada anak. Penelitian ini tidak sejalan dengan penelitian Nuzuliana \& Istiyati, (2017) bahwa kader tidak berperan aktif dalam pelaporan kasus kekerasan dikarenakan kasus kekerasan pada keluarga merupakan wilayah domestik. Kader takut dianggap mencampuri urusan rumah tangga orang lain.

Rata rata Pengetahuan kader terkait pelaporan kasus kekerasan pada anak baru sebatas ke kantor polisi. Kader belum memahami bahwa puskesmas juga bisa menjadi tempat pelaporan kasus kekerasan. Hal ini sesuai dengan penelitian Nuzuliana \& Istiyati, (2017) menjelaskan kader kurang berperan aktif dalam pelaporan kasus kekerasan pada anak sehingga pelaporan puskesmas akan kasus kekerasan tidak sesuai dengan data KPAI yang ada.

\section{SIMPULAN}

Hasil penelitian menunjukkan $70.5 \%$ kader memiliki pengetahuan tinggi terkait kekerasan pada anak. Dimana penjabaran rata rata menjawab benar setiap item pertanyaan pada definisi (54.7\%), faktor penyebab (86\%), jenis kekerasan (73\%), dampak (86\%) dan peran tenaga kesehatan terhadap kasus kekerasan anak (81.6\%) kader menjawab benar. Dari simpulan tersebut maka dapat disarankan Kepada: 1) Pihak puskesmas melakukan optimalisasi peran kader dalam pelaporan kasus kekerasan pada anak dengan memberikan sosialisasi kepada kader kesehatan terkait puskesmas tanggap kekerasan pada anak dan perempuan karena dari hasil penelitian belum semua kader mengetahui puskesmas sebagai tempat pelaporan kasus kekerasan pada anak dan perempuan, pembentukan kader kesehatan khusus identifikasi dan pelayanan kasus kekerasan pada anak, pelatihan kader kesehatan terkait identifikasi korban kekerasan dilingkungan masyarakat. 2) Kepada Kader kesehatan agar berpatisipasi aktif dalam pencegahan dan pelaporan kasus kekerasan pada anak yang terjadi di lingkungan masyarakat disekitar tempat tinggal. 3) Kepada Dinas Kesehatan diharapakan bisa melakukan sinkronisasi data antara KPAI dan kepolisian sehingga data yang ada bisa diman- 
PROFESI (Profesional Islam): Media Publikasi Penelitian 2019; Volume 16; No 2.

Website: ejournal.stikespku.ac.id

faatkan sebagai acuan pelaksnaaan program. 4) Bagi peneliti selanjutnya disarankan agar bisa meneliti terkait fakor peghambat dan pendukung kader dalam pelaksanaan pelaporan kasus kekerasan pada anak di lingkungan sekitar.

\section{REFERENSI}

Agustina, A. (2016). Kajian Tentang Upaya Pusat Peayanan Terpadu Perlindungan Perempuan dan Anak Kabupaten Sleman dalam Memberikan Perlindungan Anak Terhadap Kekerasan. Jurnal Pendidikan Kewarganegaraan dan Hukum. 1-10.

BPPM DIY. (2016). Peta Kekerasan Perempuan Anak di Kota Yogyakarta. Yogyakarta: Badan Pemberdayaan Perempuan dan Masyarakat. Available at: http://www.bppm.jogjaprov.go.id/.

Fariani, A. and Paramastri, I. (2015) Kader Posyandu sebagai Agen Pencegahan Primer Tindakan Kekerasan Seksual pada Anak, Gadjah Mada Journal of Professional Psychology. 1(2):138-149.

Fissawati, S., Indriati, G. and Elita, V. (2014) Hubungan Pengetahuan Orang Tua Tentang Kesehatan Seksual pada Anak Usia 7-12Tahun dengan Sikap Orang Tua dalam Pencegahan Kekerasan Seksual. Universitas Riau. Available at: https://media.neliti.com/media/publicatio ns/186645-ID-hubungan-pengetahuanorang-tua-tentang-k.pdf.

Gowi, A., Hamid, A. Y. S. and Nuraini, T. (2012) Penurunan Perilaku Kekerasan Orang Tua Pada Anak Usia Sekolah Melalui Latihan Asertif. Jurnal Keperawatan Indonesia 15(3): 201-206.

Gumiarti. (2008). Hubungan Status Sosial Orang Tua dengan Kekerasan Fisik Pada Anak umur 3-6 th di Kabupaten Jember. Tesis. Universitas Gadjah Mada.

IDI, Depkes RI and Unicef. (2004). Buku Pedoman Pelatihan Deteksi Dini dan Penatalaksanaan Korban Child Abuse and Neglect Bagi Tenaga Profesional. Jakarta.
Jayanti, R. and Lestari, R. (no date). Kekerasan Pada Anak Dalam Keluarga. Proceeding Seminar Nasional 'Selamatkan Generasi Bangsa dengna Membentuk Karakter Berbasis Karifan Lokal'.

Kemenkes RI. (2009). Pedoman pengembangan Puskesmas Mampu Tatalaksana Kasus Kekerasan Terhadap Perempuan dan Anak. Jakarta: Sekretaris Direktorat Jendral Bina Kesehatan Masyarakat Kementrian Kesehatan REpublik Indonesia.

KPAI. (2016). Data Kasus Perlindungan Anak Tahu 2011-2016. Jakarta: Komisi Perlindungan Anak. Available at: http:// bankdata.kpai.go.id/tabulasi-data/datakasus-se-indonesia/data-kasusperlindungan-anak-berdasarkan-lokasipengaduan-dan-pemantauan-media-seindonesia-tahun-2011-2016\#yogyakarta.

Nuzuliana, R. and Istiyati, S. (2017) Gambaran Peaksanaan Program Penanganan Kekerasan Perempuandan Anak di Puskesmas Kota Yogyakarta. Universitas Aisyiyah Yogyakarta.

Paramastri, I. (2011). Modifikasi Teori Transtero-retikal Untuk Komunitas Anti Kekerasan Seksual Pada Anak-Anak. Universitas Gadjah Mada.

Putri, A. M. and Santoso, A. (2012). Persepsi Orang Tua Tentang Kekerasan Verbal Pada Anak. Jurnal Nursing Studies. 1(1): 22-29.

Rahmadhani, L. S. (2017). Hubungan Tingkat Pengetahuan Pornografi dengan Sikap Seks Pranikah Pada Remaja Di SMA N 1 Ngrambe Kabupaten Ngawi. Skripsi. Universitas Aisyiyah Yogakarta.

Setiawan, A. (2010). Penanganan Perilaku Agresif Pada Anak. Jassi. 9: 89-96. Available at: http://ejournal.upi.edu/ index.php/ jassi/article/view/3912. 